\title{
Ensayo sobre la servidumbre. El fracaso del "capitalismo" en México
}

\author{
Kevin Aréchiga del Río \\ Centro de Investigación y Estudios Superiores en \\ Antropología Social, unidad Peninsular, México \\ kevin_arechiga@comunidad.unam.mx
}

Pedro Bracamonte y Sosa, Ensayo sobre la servidumbre. El fracaso del "capitalismo" en México, México, Centro de Investigaciones y Estudios Superiores en Antropología Social / Miguel Ángel Porrúa (Colección Peninsular), 2019.

Pedro Bracamonte y Sosa nos ofrece en el Ensayo sobre la servidumbre. El fracaso del “capitalismo" en México el resultado de más de 25 años (y 18 libros) de estudio de la Península de Yucatán a través del análisis histórico de una clase social que denomina "los despojados, incluso de esperanza” a la vez que polemiza sobre las causas de la desigualdad en el México contemporáneo. A diferencia de la mayoría de la literatura de alcance intermedio que aborda la región, este texto sobresale del resto por llevar a cabo un estudio de largo aliento que abarca más de cinco siglos (desde la Conquista hasta la actualidad) orientado más por pretensiones omniabarcadoras y multidisciplinarias que por enfoques monotemáticos, haciendo justicia a la complejidad del periodo. Para el autor este texto se justifica por la existencia de ciertos lugares comunes en la historiografía sobre Yucatán, México y "los países de estilo mexicano" que considera erróneos, pero sobre todo por la necesidad de ahondar en la comprensión de los procesos históricos de América Latina y el Caribe -una historia bien diferenciada de la europea,

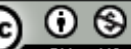

Esta obra está protegida bajo una Licencia Creative Commons Atribución-NoComercial 4.0 Internacional.

Secuencia. E-ISSN 2395-8464 http://secuencia.mora.edu.mx/ 
la norteamericana y la de países no colonizados- con categorías, si no propias, al menos apropiadas.

Para la perspectiva del marxismo ortodoxo, las ideas vertidas en este libro pueden resultar paradisiacas, pues se basan en la hipótesis de que en México no se cometió "el pecado original económico" (Marx, 2007, p. 102); sin embargo, nada menos idílico que la historia de pobreza y miseria en la región analizada. El argumento central consiste en que el desarrollo pleno del capitalismo en México se frustró por el freno a la acumulación originaria de capital y la ausencia de trabajadores libres, aplicado por las relaciones económicas y sociales de servidumbre impuestas en la Conquista y la Colonia, mismas que influyeron de forma determinante el mercado de fuerza de trabajo desde los primeros años del México Independiente hasta la actualidad. Para demostrarlo, describe detalladamente la evolución de los sistemas de trabajo en la región de la mano de pertinentes aportes documentales de Yucatán, Campeche y Cuba, recuperados del Archivo General de Indias, el Archivo Histórico Nacional en Madrid, del Archivo General del Estado de Yucatán, del Archivo Histórico Notarial en Yucatán, del Archivo General de la Nación en México y las Estadísticas del Estado de Campeche en la Biblioteca de la Universidad de Tulane, entre otros archivos), su novedosa interpretación y la discusión y reinterpretación de fuentes secundarias.

Para ilustrar la manera en que el mercado de trabajo libre y voluntario no logró consolidarse en México, dando al traste con la instauración del sistema económico capitalista, el primer capítulo da cuenta de la hibridación conceptual de tres sistemas de pensamiento: el liberalismo europeo, la tradicionalidad nativa y el pensamiento señorial hispano, así como de sus consecuencias en la economía y en las condiciones materiales de existencia de los trabajadores. La argumentación inicia con la demostración económica de la tendencia hacia la baja de la rentabilidad del trabajo esclavo y su consecuente sustitución por el peonaje, caracterizado no 
sólo por el despojo de los trabajadores de los modos de producción, sino también por la apropiación de trabajo y energía mediante el sistema de deudas y coacciones extraeconómicas.

Según sus hallazgos, en un contexto de poca oferta en el mercado de trabajo, la deuda tiene la función de garantizar el arraigo del trabajador, pero sobre todo el precio de sus futuros jornales. A pesar de este mecanismo y como contraste con la esclavitud, el peonaje al largo plazo resulta más rentable porque "permite transferir buena parte del costo de la misma supervivencia al individuo y a la familia, pero reteniendo a favor de los amos, un alto nivel de control extraeconómico sobre el trabajo” (Bracamonte, 2019, p. 69). Dicho control extraeconómico se deja sentir jurídica e ideológicamente mediante la promulgación de leyes que propician el aumento en el índice de peonización mediante diversas estrategias para favorecer el despojo agrario y la creencia de la superioridad blanca sobre las otras razas. A partir de estos datos se hace una relectura de las causas de la Guerra de Castas, dándole a la pérdida de la libertad, tal y como los mayas la concibieron, un lugar preponderante.

Además de los indicadores económicos, el estudio del fracaso del capitalismo en México incluye reflexiones acerca de las premisas fundamentales del pensamiento señorial que se enfrentaron con la tradicionalidad indígena por más de tres siglos. Esto permite comprender que no se trata sólo de desprecio racial, sino que nos encontramos ante la presencia de la racionalización de dicha creencia -y después nacionalizada por los regímenes liberales- utilizada para ganar dinero sin atender a las pautas del capitalismo mundial. La continuidad histórica de dicho sistema de pensamiento se traduce en la actualidad en un Estado etnocida que continúa con una tendencia hacia la indigenización de un segmento de la población con la finalidad de favorecer la concentración de riqueza apoyada en salarios que están siempre debajo de la reproducción física y social de los trabajadores.

Una de las principales aportaciones de este libro es el tratamiento de las fuentes primarias, pues son un acceso privilegiado para conocer a detalle en qué consistió la servidumbre 
por peonaje. Partiendo de evidencia concreta como la constatación de la miseria en la que viven millones de mexicanos actualmente, el Ensayo hace una reconstrucción histórica de dichas condiciones materiales de existencia. Los capítulos cinco, seis y siete son ricos en información, indicadores, tablas y estadísticas sobre los trabajadores de las haciendas meridanas, los colonos en Cuba y los "asalariados" en Campeche durante el siglo XIX. Gracias a estos capítulos podemos conocer cuánto henequén salía anualmente por el puerto de Sisal durante su boom productivo, la composición étnica de los trabajadores en las haciendas y las jerarquías entre los tipos de jornaleros, así como sus tareas y el pago que recibía cada uno. Toda esta evidencia empírica es la que le permite asegurar al autor que la herencia señorial y la tradicionalidad indígena, en su contacto con el liberalismo económico y político, fueron determinantes para evadir el trabajo libre asalariado.

En contra de la premisa ampliamente aceptada de una pretendida homogeneidad geográfica, cultural e histórica en la Península de Yucatán (Savarino, 2012, p. 87), Pedro Bracamonte da cuenta de una gran diversidad microrregional que, mediante un ejercicio de abstracción, le permite hacer generalizaciones para comprender por qué el capitalismo fracasó en las naciones de herencia colonial y los países con procesos históricos similares. En este sentido, y no conforme con desechar dicho consenso en la historiografía de Yucatán, Bracamonte y Sosa va más allá al descartar la existencia del capitalismo en América Latina y, por lo tanto, la incapacidad de los postulados de la teoría marxista (pensada para Inglaterra y Europa) de brindar explicaciones certeras y soluciones plausibles en esta parte del planeta. No obstante, en algún momento de la historia una de cada tres personas era gobernada por un régimen político inspirado en las ideas de Karl Marx (Hobsbawm, 2012, p. 14), para el autor las premisas vertidas en El Capital no bastan para explicar y comprender la complejidad de su región de estudio. En este sentido este texto da con las causas históricas de la desigualdad en México e invita a sustituir la importación de teorías extranjeras -europeas en su mayor parte- mediante la generación de 
teoría que se adecúe a las especificidades de Latinoamérica. No se trata, entonces, de una relectura original del marxismo, sino de una reflexión sobre las implicaciones del estudio de los países latinoamericanos con categorías sin sustento empírico y de la construcción de una teoría más adecuada para emprender dicha tarea.

Además de una comprensión profunda del pasado colonial de la región y de las carencias teóricas de quienes participan en la importación teorías europeas para explicar realidades que les son ajenas, el autor acierta al entender a la pobreza como un problema del presente que está bien anclado en la historia, pero que se orienta peligrosamente hacia el largo plazo. En este sentido, el autor hace una convocatoria en las conclusiones para formar un nuevo partido político ajeno al gasto público y privado; para crear una nueva Constitución política bien anclada en la historia, -pues "México solo tendrá una segunda oportunidad como nación cuando se mire en su propia historia” (Bracamonte, 2019, p. 424)-; y, por qué no, para dar un nombre -todavía inédito- al nuevo modelo económico que funcione para dar respuestas a las problemáticas regionales.

Si bien el texto echa luz sobre aspectos que no habían recibido la atención que merecen -como las raíces históricas de la pobreza actual- y desecha algunas ideas falsas, pero bien establecidas en la literatura historiográfica sobre Yucatán -como la de la supuesta homogeneidad regional-, pueden hacérsele al texto algunos reproches. De entrada, y tal vez debido a la larga extensión temporal del estudio, hay en el libro grandes saltos temporales que dificultan rastrear las rupturas continuidades respecto del trabajo y la pobreza durante el periodo de tiempo estudiado. En este tenor, el autor cuenta con mucha documentación sobre algunos siglos, pero muy poca sobre otros. Asimismo, no se incluye una definición operativa de uno de sus conceptos centrales y la evidencia misma del fracaso del capitalismo en México, según Pedro Bracamonte. ¿Quiénes son, verdaderamente, los despojados de esperanza? Pareciera que hay una discrepancia entre las pretensiones económicas del concepto y su matriz cultural, su dimensión 
subjetiva y su actitud valoradora. De la misma manera, y al igual que Marx cuando trata de la falsa conciencia (Sloterdijk, 2003, p. 61), el autor se revela un tanto funcionalista, pues decreta que los miembros productivos de la sociedad deben interiorizar determinadas formas de sentir al afirmar que un gran sector de la población, no conforme con vivir en unas condiciones materiales de existencia miserables, tampoco tiene un ápice de esperanza con miras hacia la mejora de sus condiciones actuales y futuras. La carencia de esperanza no sólo puede resultar cosificadora, sino que su pesimismo respecto de los años venideros les resta pertinencia a las propuestas de participación política y reforma constitucional planteadas en el capítulo final.

A pesar de que el autor de este libro lo presenta como la conclusión de una larga trayectoria en el estudio de la península yucateca, éste en realidad no hace sino todo lo contrario, pues abre nuevas preguntas y replantea viejas cuestiones que se daban por zanjadas. ¿Cómo comprender el desarrollo económico mexicano de los siglos XIX y XX a sabiendas de que la acumulación originaria no tuvo lugar en la historia del país? ¿Cómo se relaciona el capitalismo mundial -en caso de que se demuestre su existencia- con el sistema económico de la región? ¿Cómo construir un proyecto que tenga bien presente la influencia que ejerce el pasado sobre el tiempo presente? Estas y otras interrogantes surgen de la lectura del libro, y no cabe duda de que en los próximos años surgirán diversas investigaciones que busquen darles respuesta.

\section{Referencias}

Hobsbawm, E. (2011). Cómo cambiar el mundo: Marx y el marxismo 1840-2011. España: Editorial Crítica.

Marx, K. (2007). El Capital. España: Akal.

Savarino, F. (2012). Yucatán ¿Un caso atípico en la Revolución Mexicana? En F. Paoli, et al, La Revolución en Yucatán. Nuevos ensayos (pp. 83-128). México: CEPSA.

Sloterdijk, P. (2003). Crítica de la razón cínica. España: Siruela. 